proteins and an excellent chapter by T. A. J. Prankerd on 'Metabolic Aberration of Erythrocytes'.

Many would appreciate the inclusion of a comprehensive section on radioactive isotopes in hæmatology, although some aspects of their uses are dealt with e.g. by C. G. Craddock 'The Production, Utilization and Destruction of White Blood Cells' and by T. T. Odell and R. M. Kniseley ' The Origin, Life Span, Regulation and Fate of Blood Platelets'.

The hæmoglobinopathies ' have been grudgingly left out' as Tocantins points out in his introduction, and he also writes that the choice of subjects and authors was not an easy task.

\section{Heart Disease-Some Ways to Prevent It}

A. R. Southwood, M.D., M.S., M.R.c.P. Pp. viii + 153, illustrated. William Heinemann Medical Books. 1962. 17s. $6 d$.

This small book is an amplification of the author's Milroy Lectures delivered at the Royal College of Physicians, London, in 1959. Dr. Southwood was formerly Director General of Public Health in South Australia, and his book consists of a survey of the incidence of various cardiovascular diseases (most of the statistics are Australian), followed by a summary of the known xtiological factors in the main groups (congenital, rheumatic, syphilitic, hypertensive and arterio sclerotic) and some hints on their prevention.

These pages bring home to the reader that though the hæmodynamics and pathology of cardiovascular disease have come to be much better understood in the past three decades, there is still surprisingly little we can do to prevent the onset of the most prevalent disorders, hypertension and atherosclerosis. It is well, too, to be reminded what a small fraction ( 1 to $2 \%$ ) of cardiovascular diseases met in practice are contributed by the congenital group, which looms so large in specialist cardiac centres.

The work contains little clinical information that is not familiar to most practising physicians, and will probably be of most value to the student, social worker or layman. It is a readable book which puts its subject nicely in perspective and contains some useful historical and modern references. If preventive measures in some fields of cardiology seem a little meagre, that is hardly the author's fault.

\section{Surgery-Principles and Practice}

H. N. Harkins, M.D., PH.D., C. A. Moyer, M.D., J. E. RhoADS, M.D., D.SC.(MED.) and J. G. AlleN, M.D. Second edition. Pp. xxiv + 1,495, with 652 illustrations. London: Pitman Medical. 1962. £6 6 s.

Second editions are invariably improvements on the first, and this volume is no exception. The layout and general presentation of this large book is excellent, and the text is presented in an easily read style. The diagrams are first class but some of the photographs might be improved in further editions, the detail not always being as clear as it might be. The inclusion of chapters on the history of surgery and military surgery makes refreshing reading, and the latter is especially pertinent in view of the increased interest in traumatic surgery generally. Certain sections (for instance, that on gynæcology) in a textbook of general surgery, may be an innovation for the English reader, and although the authors have set out to make the book as comprehensive as possible, their exclusion might have made it a little less lengthy.

This criticism apart, it is an excellent textbook for the graduate student and also for the postgraduate reading for higher surgical examinations: though one or two sections, for instance the complications of certain operations, may not be comprehensive enough for the latter. \section{The Homolytic Anamias, Congenital and $\overrightarrow{\bar{\omega}}$
Acquired-Part 2. The Auto Immune Anamins} J. V. DACIE, M.D.(LOND.), HON. M.D.(UPPSALG), F.R.c.P. Second edition. Pp. vi +378 , with fir illustrations. London: J. and A. Churchel. 1962. 50s.

This is the second edition of this standard work by one of the leading authorities. Since the first edition in 1954 the subject has expanded to such an extent that three volumes instead of one are necessary. The first volume was published in 1960 and the final volume $\overrightarrow{c t s}$ promised in two year's time. The present volume deats with the auto-immune hæmolytic anæmias and chapter numbers and headings from the first edition $\frac{\text { ffe }}{3}$ retained, although the reading matter is increased from 164 to 366 pages. This book will require no recotymendation to hæmatologists, to others it will mainly be used as a reference book; both will find it lucid afd exhaustively informative. Nevertheless there are one or two minor criticisms all concerned with the undoubted disadvantage of the three volumes not being published simultaneously. Unavoidably there are references to the unpublished final volume, and in discussing te association between hæmolytic anæmia and thrombocytopenia Professor Dacie is careful to discuss onty the association with auto-immune hæmolytic anærfia because thrombotic thrombocytopenia is included in the final volume. The index, whilst comprehensive, ors separate for each volume. Perhaps joint authorskip might be an answer to this problem, for all would ofgree on the undoubted benefit of the three volumes apperisg together.

\section{The Acute Abdomen in Rhyme}

'ZETA'. Fourth edition. Pp. vii + 102, illustratêd by Peter Collingwood. London: H. K. Lev?s. I962. Ios. $6 d$.

' So if you would avoid mistakes, I hardly need@̊ mention,

Routine examination is the method of prevention,

This little book remains a masterpiece, although perhaps not quite the masterpiece that it was 15 years ago. Even emergency surgery has fashions and thete are few surgeons nowadays who would approve of a $\mathrm{r}$-in. abdominal incision under local anæsthesia in order to differentiate between pleuritic pain and appendicitus! Nor could typhoid any longer be regarded as one of the common alternatives to acute appendicitis. The " callow cocky youth', however, 'who from his books has leaont much doubtful truth', still misses perforated pep ic ulcers by scorning the opinion of the "old and ignorant G.P.' Few textbooks have ever been written whieh have surpassed ' Zeta's ' description of acute intestipal obstruction, especially that deadly and insidious tye due to a high jejunal lesion. This book can still be read by old and young alike for instruction and not only for amusement.

\section{Recent Advances in Pharmacology}

J. M. RoBSon, M.D., D.SC., F.R.S.E., and R.F్ STACEY, M.A., M.D. Third edition. Pp. $x+406$, with 68 illustrations. London: J. \& A. Church 1 . 1962. 545 .

Apart from Professor Stacey replacing Professor Keele as co-editor, this new edition of "Recent Advanges 
in Pharmacology' differs from its predecessor in several ways. With the geometrical progression of new knowledge in so many fields, the editors have wisely abandoned the attempt to cover everything themselves and have invited several experts to contribute in their own subjects. The fact that four of these are clinicians is, as the editors point out, an indication of present trends in research. Another important change is in format. The new edition, perhaps due to recent advances in printing, is much more attractively produced than its predecessor.

The range of subjects considered is wide and it is difficult to think of any significant omissions. There are four chapters devoted to the currently interesting and related subjects of pharmacologically active substances in the C.N.S., psychotropic drugs, catechol amines and 5-hydroxytryptamine, including a section on the clinical use of psychotropic drugs by C. M. B. Pare. M. Schachter deals with the slightly elusive subject of pharmacologically active polypeptides. W. J. H. Butterfield and R. F. Mahler discuss carbohydrate metabolism in diabetes, insulin and the oral hypoglycæemic agents and $L$. G. Goodwin compares new and old drugs in the treatment of tropical diseases and parasitic infestations. Perhaps the best chapter is contributed by M. D. Milne, who not only discusses diuretic agents, but also gives a clear and concise account of current theories of renal physiology, with the mode of action of the drugs explained, as far as possible, in the light of these theories. Other subjects covered include steroid drugs, chemotherapeutic agents (including the newest penicillins), hypotensive agents and miscellaneous new drugs.

This new edition is an excellent book and can be thoroughly recommended, not only to pharmacologists, but to any physician interested in the pharmacological and physiological background to drug therapy.

\section{Surgeon at the Bedside}

Stephen Power, M.D., M.S., F.R.C.S. Pp. vii +162 , illustrated. London: William Heinemann Medical Books. 1962. I $7 s .6 d$.

This little book gives advice on practical surgical diagnosis. It is concerned with the methodical approach to clinical surgery and does not attempt to be a treatise of differential diagnosis. The importance of detailed history-taking is rightly stressed, and tips are given on how to obtain essential history rapidly and tactfully. The chapters on the history, the evaluation of physical signs, and the uses and limitations of radiology and endoscopy are excellent guides backed by the author's long experience in abdominal surgery and urology. The cautions as to when history, physical signs, and investigations may actually mislead in diagnosis are especially useful; such situations occur not uncommonly and it is right that students should be aware of these difficulties from the start. The observations on observer error are welcome and enlightening.

Some statements made might well be challenged, for example: "Vomiting seldom occurs with other than abdominal pain'; 'A catheter should be used in the female' (for obtaining urine specimens); 'A red cell count is almost as necessary as a hæmoglobin reading'. The few 'humorous' illustrations are either irrelevent or tasteless and would have been better omitted. Despite these minor reservations this is a concise and readable book which contains much common-sense and wisdom. It could be read in a short time and with profit by senior students and house surgeons.
A History of American Pathology

ESMOND R. LoNG, M.D., PH.D. Pp. xiv +460, illustrated. Springfield, Illinois: Charles $\mathrm{C}$ Thomas. 1962. $\$ 12.50$.

Those who read with delight Long's 'A History of Pathology' (1928), will be disappointed that that masterly performance has not been repeated in the present volume, which is essentially a vast chronology of dates of birth, professorial appointment and death, of all American and Canadian Pathologists, with a broad interpretation of the title in the earlier less specialised era. Each entry-about 1,500 names occur-receives a notice according to importance, is Welch alone being distinguished by a chapter woven around his professional life, but most of the book is patterned on the Book of Chronicles rather than Aubrey's Brief Lives. The backcloth to the names consists of the institutions they graced, the details of the evolving administration, the founding of licensing bodies, medical schools, societies and journals, and we are reminded that the United States is a federal union, with regional variation in the timing and pattern of development.

The truth is, that in an age of rapid communication $\stackrel{+}{\oplus}$ and easy travel-the period covered by three-quarters $\overrightarrow{\vec{t}}$ of the book down to the present day-regional differences in the theory, practice and teaching of such broad $\stackrel{1}{\alpha}$ disciplines as pathology commands, become of quite $\mathrm{O}$ secondary importance, and of local, or at most national interest. Clearly for historical, geographical and economic reasons, some American contributions to the $\mathbb{T}$ general body of pathological knowledge are unique. An account of such achievements, with characte studies, incidents, and judicious commentaries ang opinions blended into the narrative would form of fairly distinctive history of American pathology, to be assimilated by the general reader. Nowhere in the $\mathrm{\omega}$ present text do we have any sense of intimacy with the American scene: there is no lingering, no discursive aside. It is the dust of the ground waiting for the breath of life to be breathed into it.

The Exocrine Pancreas, Normal and Abnormal Functions

Ciba Foundation Symposium. Editors: A. V. S. de Reuck, and Margaret P. Cameron. Pp. xii + 390. London: J. \& A. Churchill. 1962. 55 s.

A small conference of twenty-eight distinguished investigators has a more refined and creative atmosphere than is possible from large international meetings. This symposium is the first that the Ciba Foundation has devoted to any part of the alimentary tract, and may it be the first of others. The book, well produced, is a record of deliberations covering three days, under the chairmanship of Professor Sheila Sherlock. It has many illustrations such as photographs from the electron microscope, electrophoretic strips, graphs and histograms, is properly documented with references, and fully indexed.

The inelegant title may not convey to every reader its scope. Exocrine, he may correctly conclude, is the $\sigma$ opposite to endocrine and refers to the external secretion $N$ This indeed is covered fully; and a great deal more. $N$ even though insulin and the Zollinger-Ellison Syndrome $\omega$ are excluded. The first subject is the pancreatic cell, its 0 ultrastructure and histochemistry, and the physiology 0 of zymogen granules and other sub-cellular particles which may be precursors of the enzyme of pancreatic $\mathbb{D}$ juice. Sections concerning the nature and physiological control of pancreatic secretion lead on naturally to the 